\title{
Evaluation of Harmonic Structure Obtained in Mechanically Milled Powders and Pulse Plasma Sintered Compacts of Austenitic Steel
}

\author{
Dariusz Oleszak*, Aleksandra Sadurska and Grzegorz Cieślak (D)
}

check for updates

Citation: Oleszak, D.; Sadurska, A.; Cieślak, G. Evaluation of Harmonic Structure Obtained in Mechanically Milled Powders and Pulse Plasma Sintered Compacts of Austenitic Steel. Metals 2021, 11, 386. https:// doi.org/10.3390/met11030386

Academic Editor: Antonio Mateo

Received: 31 January 2021

Accepted: 23 February 2021

Published: 26 February 2021

Publisher's Note: MDPI stays neutral with regard to jurisdictional claims in published maps and institutional affiliations.

Copyright: (c) 2021 by the authors. Licensee MDPI, Basel, Switzerland. This article is an open access article distributed under the terms and conditions of the Creative Commons Attribution (CC BY) license (https:// creativecommons.org/licenses/by/ $4.0 /)$.
Faculty of Materials Science and Engineering, Warsaw University of Technology, 02-507 Warszawa, Poland; aleksandra.sadurska.stud@pw.edu.pl (A.S.); grzegorz.cieslak@pw.edu.pl (G.C.)

* Correspondence: dariusz.oleszak@pw.edu.pl; Tel.: +48-22-2348408

\begin{abstract}
The paper describes an attempt to obtain harmonic structure (HS) in AISI308L steel. Harmonic structure is the term related to the microstructure fabricated by mechanical milling of metallic powders under soft milling conditions, resulting in the formation of plastically deformed, grain-refined shell and unchanged core. This microstructure can be preserved after successful powder compaction. The powders of AISI308L steel were milled under soft condition up to $50 \mathrm{~h}$ and then compacted by pulse plasma sintering at $900-1100{ }^{\circ} \mathrm{C}$. For powders and compacts XRD, SEM and hardness measurements were applied as characterization techniques. The milling process resulted in austenite transformation into nanocrystalline ferrite and formation of grain refined outer layer. The applied pulse plasma sintering parameters allowed preservation of this microstructure and manufacturing of compacts with homogeneous distribution of elements, relative density above 95\% and hardness in the range 167-185 HV, depending on sintering temperature. Simultaneously, the starting phase composition was restored, i.e., austenite with $12 \%$ contribution of ferrite. The crystallite size of austenite was about $20 \mathrm{~nm}$ and was significantly smaller then in starting powders.
\end{abstract}

Keywords: mechanical milling; austenitic steel powders; harmonic structure; pulse plasma sintering

\section{Introduction}

The expected properties of the materials can be achieved at different stages of their processing. At first, it is possible to modify the properties by changing chemical or phase composition, resulting in specific microstructure. Then, already made material can be submitted to heat or plastic treatment for further improvement of properties. However, the processing time should be as short as possible, according to environmental and industrial expectations. One of the manufacturing techniques commonly used is powder metallurgy. This technique includes many various specific processes. In many cases the desired final microstructure can be obtained by mechanical alloying/milling of powders followed by their compaction. Mechanical alloying is widely applied to produce many types of phases or structures, like amorphous, nanocrystalline, intermetallics, extended solid solutions, composite materials, etc. [1]. This technique can also result in the formation of so called harmonic structure. If mechanical milling process is performed in soft energy conditions, two areas are distinguishable on the cross section of powder particle. The outer part of the powder particles is intensively plastically deformed and significant refinement of microstructure can be observed, while interior of powder particles remain unchanged. The fine-grained outside layer is called shell, while the unchanged coarse-grained area inside the particle-core. The thickness of shell part depends on milling parameters.

The term harmonic structure refers also to the compacts obtained after successful sintering of the powders, i.e., allowing the preservation of harmonic structure observed after milling. In bulk materials (compacts), severely deformed outer parts of particles create a matrix in which coarse-grained areas are embedded [2]. The contribution of these 
two types of microstructures (refined and coarse-grained) depends on milling conditions and, additionally, on sintering parameters. The obtained material looks like composite with nanocrystalline matrix and microcrystalline reinforcement, both revealing the same chemical and phase composition, but different microstructure (grain size). Therefore, this new concept is quite different from traditional ones, based on the idea of nanocrystalline reinforcing particles placed in traditional microcrystalline matrix. It is expected that such material can show an excellent combination of strength and ductility simultaneously.

The concept of harmonic structure has been created and developed in Japan, by research group led by K. Ameyama [3]. They studied various materials, like copper [4], Co-Cr-Mo [5,6], Ni [7], stainless steel [8,9] and titanium and its alloys [2,10,11], with successful obtaining of the harmonic structure in bulk (sintered) materials. Some papers were devoted to fatigue behavior of HS [12,13], influence of thermomechanical treatment [14] or possibility of obtaining HS in high entropy alloys [15]. In the present work the attempt has been made to create harmonic structure in the powders and compacts of austenitic AISI 308L steel.

\section{Materials and Methods}

The chemical composition of steel purchased in the form of rod (10 $\mathrm{mm}$ diameter) from ESAB Welding Products ${ }^{\circledR}$, Sweden, corresponding AISI 308L type, is given in Table 1. Moreover, according to manufacturer, the phase composition is $91 \%$ of austenite and about $9 \%$ of ferrite.

Table 1. Chemical composition of the steel studied (Fe-bal.).

\begin{tabular}{ccccccc}
\hline $\mathbf{C}$ & $\mathbf{M n}$ & $\mathbf{S i}$ & $\mathbf{N i}$ & $\mathbf{C r}$ & $\mathbf{M o}$ & $\mathbf{C u}$ \\
\hline 0.01 & 1.8 & 0.9 & 10.5 & 19.9 & 0.15 & 0.10 \\
\hline
\end{tabular}

The powders were fabricated by ultrasonic atomization process. As received, powders were spherical in shape and revealed average particle size about 70-100 $\mu \mathrm{m}$. Next, the powders were submitted to mechanical milling process in a Fritsch P5 planetary ball mill for various milling times, ranging from 1 to $50 \mathrm{~h}$. Hardened steel vial and balls $(10 \mathrm{~mm}$ in diameter) were applied. The milling processes of $10 \mathrm{~g}$ of powders were performed in argon protective atmosphere, at room temperature, applying a low rotational speed of $150 \mathrm{rpm}$. Two processes with different ball-to-powder weight ratios (BPR) were conducted: 2:1 and 4:1. Parameters of milling were selected on the basis of the literature data related to formation of harmonic structure in various powders and were very soft, compared to standard milling parameters of metallic powders. Subsequently, the selected powders (BPR 2:1, $50 \mathrm{~h}$ ) were sintered by pulse plasma sintering (PPS) method under pressure of $50 \mathrm{MPa}$ for $5 \mathrm{~min}$ at 900,1000 and $1100{ }^{\circ} \mathrm{C}$. The microstructural characterization of the initial powder, milled powder and sintered compacts was performed by scanning electron microscopy (scanning electron microscopy, SEM, Hitachi S3500, Hitachi Ltd., Tokyo, Japan), equipped with energy dispersive spectroscopy (EDS) unit allowing determination of distribution of elements in sintered compacts. The changes of phase composition were monitored by X-diffraction method (x-ray diffraction, XRD, Rigaku MiniFlex II, CuK $\alpha$ radiation, $\lambda=0.15418 \mathrm{~nm}$ ). Based on XRD research, the size of crystallites and the value of lattice parameter were calculated, applying Scherrer and Nelson-Riley approaches, respectively. The mechanical properties were estimated by Vickers hardness measurements under a load of $10 \mathrm{~kg}$. At least 5 indentations were performed. The density of the compacts was measured by standard Archimedes method.

\section{Results}

The starting powder particles and after milling for $50 \mathrm{~h}$ (BPR 2:1) are shown in Figure 1a,b, respectively. The particles after atomization show typical spherical morphology. Milling results in the formation of plastically deformed outer layer (shell). Moreover, some porosity is observed in the shell and cracks in the core. Continuation of the milling 
process for longer time does not introduce any visible changes in powder size, morphology and thickness of surface layer. For the process performed for BPR 4:1 similar behavior of the powders was observed.

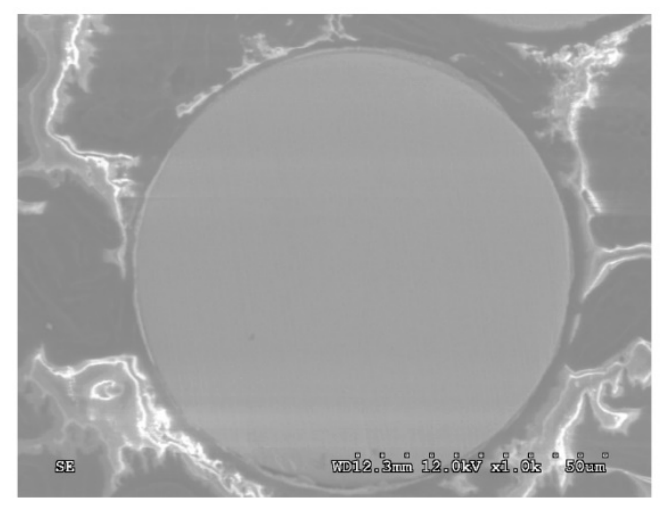

(a)

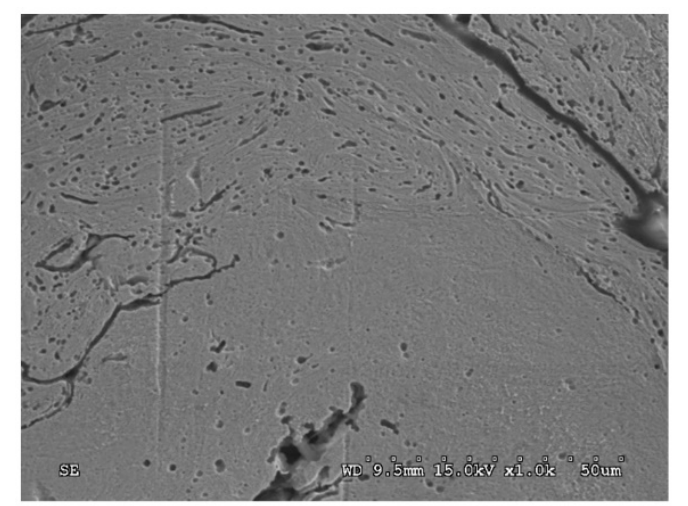

(b)

Figure 1. (a) Starting powder particle after atomization; (b) Powder particle after milling for $50 \mathrm{~h}$ (BPR 2:1).

In order to follow possible phase transformation upon milling, XRD studies have been performed. The sequence of XRD patterns recorded for the powders milled for various times (BPR 2:1) are collected in Figure 2a.

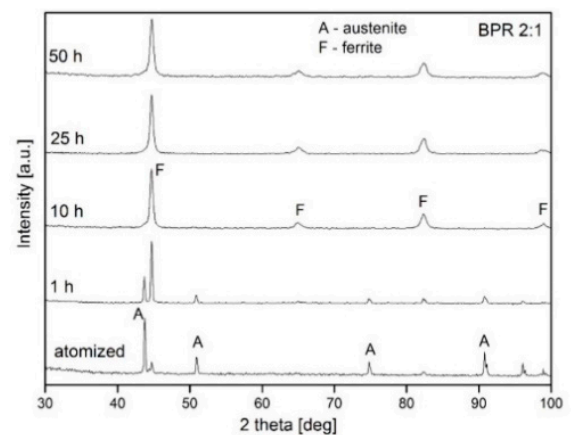

(a)

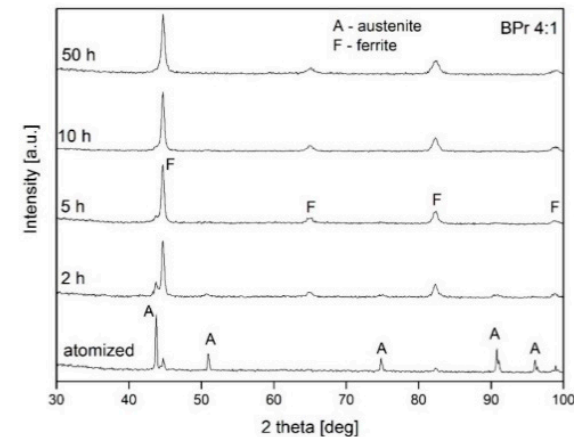

(b)

Figure 2. (a) XRD patterns recorded for the powders milled up to $50 \mathrm{~h}$, BPR 2:1; A-austenite, F-ferrite; (b) XRD patterns recorded for the powders milled up to $50 \mathrm{~h}$ (BPR 4:1); A-austenite, F-ferrite.

For starting powders, austenite and ferrite were detected as the existing phases. The ferrite contribution in the powder structure estimated from X-ray pattern was about $15 \%$, i.e., slightly higher than the value reported by the manufacturer in the starting rod submitted to atomization. After short milling time, the diffraction lines of austenite disappeared, and $10 \mathrm{~h}$ of processing results in the bcc-phase lines in the pattern only, suggesting ferrite existence. Similar strain-induced transformation of austenite to ferrite has alreadybeen reported [16]. The possible phenomenon of austenite-martensite transformation due to milling of steel powders has also been described as strain induced transition [17], however, the milling conditions applied seem to be too soft for this type of transformation. Moreover, the analysis performed indicates that the recorded lines do not belong to martensite (ICDD 00-044-1289).

The crystallite size of ferrite, calculated by Scherrer method, was about $30 \mathrm{~nm}$ and $28 \mathrm{~nm}( \pm 3 \mathrm{~nm})$ for milling time 10 and $50 \mathrm{~h}$, respectively. The value of lattice parameter of ferrite did not change significantly upon milling. For starting powder and after $50 \mathrm{~h}$ of 
processing, the values of $2.869 \AA$ and $2.872 \AA \pm 0.005 \AA$ were obtained. Lattice parameter of starting austenite was calculated as $3.596 \pm 0.005 \AA$.

XRD studies were also performed for the powders milled with BPR 4:1 and the registered X-ray patterns are presented in Figure $2 \mathrm{~b}$. Very similar sequence of phase transformations were observed. The diffraction lines of austenite disappeared after $10 \mathrm{~h}$ of processing. The calculated values of crystallite size and lattice parameter for ferrite after $50 \mathrm{~h}$ of milling were $20 \pm 3 \mathrm{~nm}$ and $2.871 \pm 0.005 \AA$, respectively.

Next, the powders after $50 \mathrm{~h}$ of milling with BPR 2:1 were subjected to pulse plasma sintering at 900,1000 and $1100{ }^{\circ} \mathrm{C}$, and the surface of the obtained sinters was observed by SEM. The micrographs showing the surface of the sample sintered at 900 and $1100{ }^{\circ} \mathrm{C}$ are presented in Figure 3a,b, respectively. One can notice that outer regions (shells) of milled powders transformed into continuous matrix in the form of layers surrounding inner parts of powders (cores). Some porosity was also observed. The measured related density of the sinters processed at 900 and $1100{ }^{\circ} \mathrm{C}$ was 95.9 and $98.1 \%$, respectively.

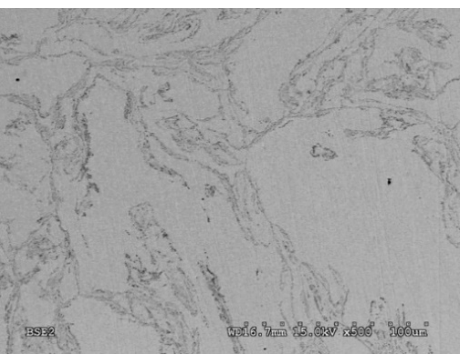

(a)

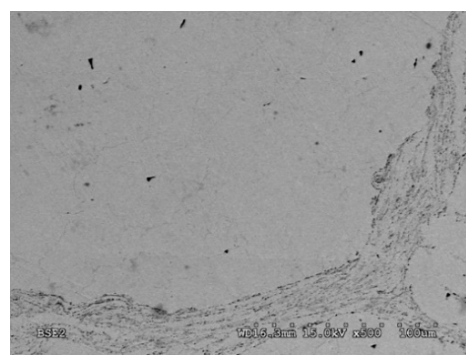

(b)

Figure 3. SEM micrographs of the sinters processed at (a) $900{ }^{\circ} \mathrm{C},(\mathbf{b}) 1100{ }^{\circ} \mathrm{C}$.

In order to check the distribution of the elements, mapping was done for the sample sintered at $900{ }^{\circ} \mathrm{C}$ (Figure 4). The obtained results testify the uniform distribution of $\mathrm{Fe}, \mathrm{Cr}$, $\mathrm{Ni}$ and Mo in the sinter.
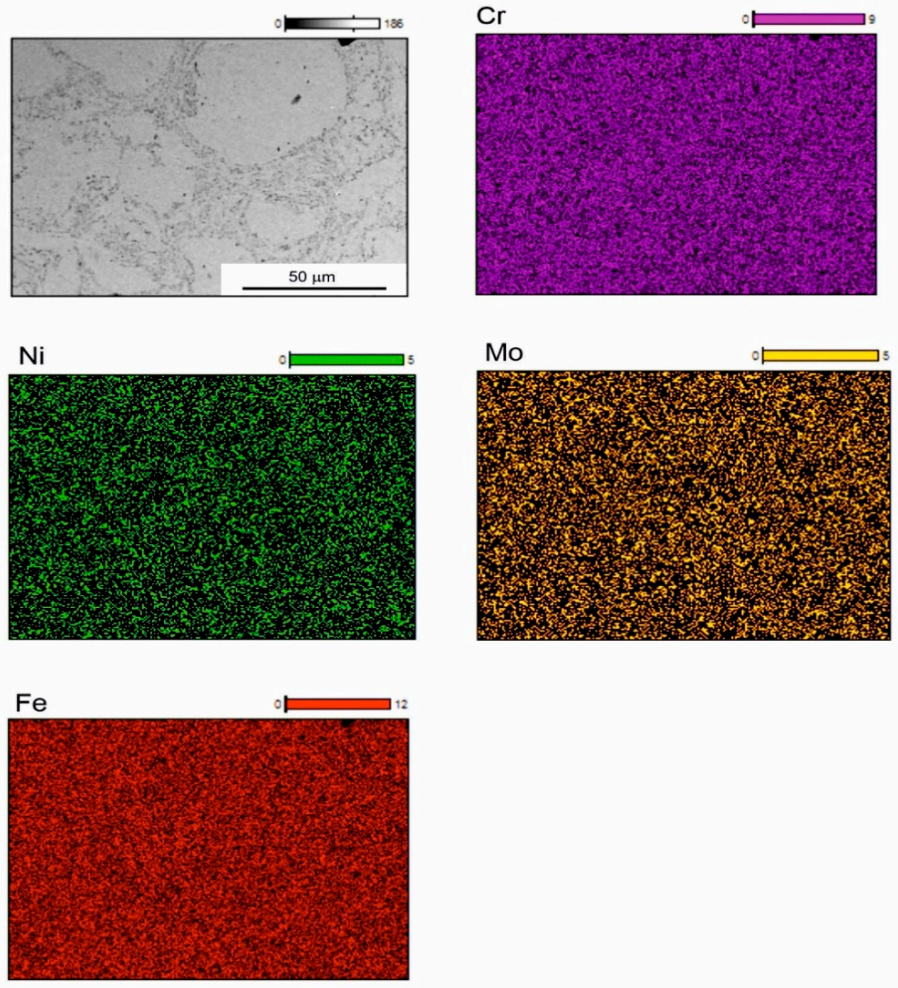

Figure 4. Distribution of the elements in the sample sintered at $900{ }^{\circ} \mathrm{C}$. 
In order to verify possible phase transformations during sintering, $\mathrm{XRD}$ studies were performed for sinters (Figure 5). For comparison the X-ray patterns for powders atomized and milled for $50 \mathrm{~h}$ are also included.

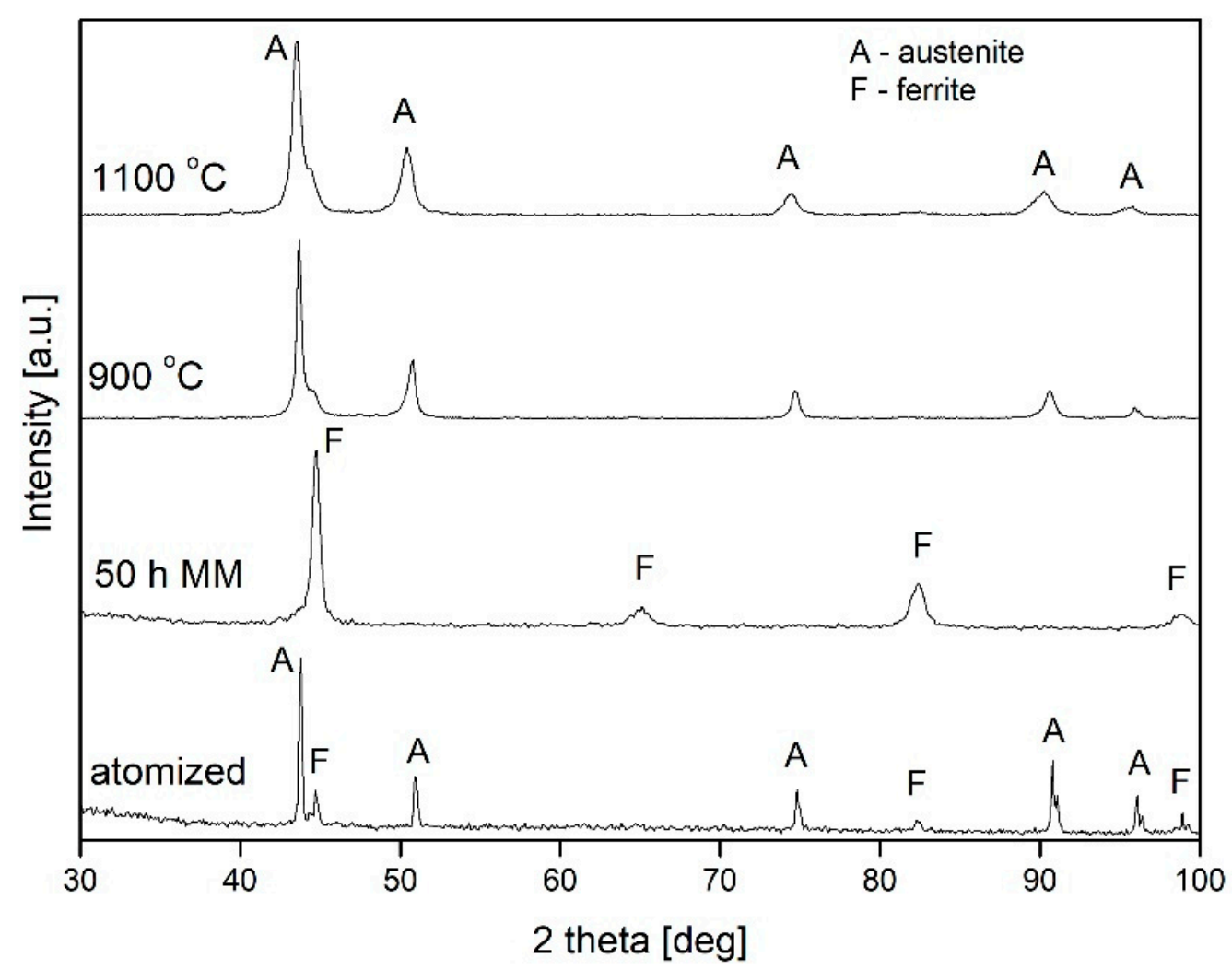

Figure 5. XRD patterns recorded for the atomized and milled powders as well as for sinters.

XRD studies show that the patterns for sintered samples qualitatively are very similar to the one recorded for atomized powder, i.e., the diffraction lines of austenite are clearly visible, with some participation of ferrite in the structure. The contribution of ferrite is calculated as $12 \%$. Simultaneously, the registered diffraction lines are broadened compared to starting powder. The crystallite size of austenite, calculated by Scherrer method, is about $20 \mathrm{~nm}( \pm 3 \mathrm{~nm})$ for both compacts. The calculated value of austenite lattice parameter for the sample sintered at $900{ }^{\circ} \mathrm{C}$ was $3.597 \pm 0.005 \AA$, i.e., very close to the value for starting powder.

For compacts' mechanical properties determination, hardness measurements were performed applying Vickers method. For the samples processed at 900,1000 and $1100{ }^{\circ} \mathrm{C}$, the obtained values were 167, 170 and $185 \mathrm{HV}$, respectively, with standard deviation of $17 \mathrm{HV}$. It can be concluded that a slightly increasing hardness is resulting from the increase of samples' density rather than from microstructure changes.

\section{Discussion}

An attempt has been made to obtain so-called harmonic structure in austenitic AISI 308L steel, both in powders and compacts. The milling conditions applied for manufacturing of outer, grain-refined layer (shell) were very soft, therefore, the microstructural changes introduced were not very severe. However, these conditions were sufficient for strain induced transformation from austenite to ferrite. The ferrite obtained after milling revealed nanocrystalline structure, with crystallite size about $30 \mathrm{~nm}$. Sintering processes allowed for manufacturing compacts with harmonic structure and uniform distribution of the elements. It is also important to underline that sintering parameters were sufficient to restore the phase composition existing before milling. Again austenite appeared as a dominating phase. Moreover, its crystallite size was at the level of $20 \mathrm{~nm}$, smaller than the 
one calculated for ferrite after milling, and significantly smaller than the crystallite size of austenite in starting powder (which was above $100 \mathrm{~nm}$ ). Therefore, the applied procedure allowed for the obtaining of nanostructured samples. The measured hardness was similar to the values typical for this kind of steel. This fact can derive from relatively small contribution of shell in the structure (very soft mechanical milling conditions) and porosity up to $4 \%$. However, it is difficult to compare the previous results reported for austenitic steel powders, because the possible phase transformation upon milling was not considered and checked during the studies. The only changeable parameter was contribution of shell in the microstructure (thickness of the layer) as a result of variable milling time. Simply there was an assumption that milling conditions are so soft that strain induced transformation of austenite was not possible. Our studies revealed that even gentle milling can result in such transition.

Future research directions should be related to intensification of milling conditions in order to attain a higher contribution of shell, density improvement and microhardness measurements allowing for separate measurement of mechanical properties of core and shell.

\section{Conclusions}

In this study, the attempt was made to create harmonic structure in the powders and compacts of austenitic AISI 308L steel, applying mechanical milling of powders and their compaction.

The following conclusions may be drawn:

- $\quad$ soft mechanical milling conditions applied, resulted in the formation of harmonic structure in the processed powders, i.e., plastically deformed and refined (crystallite size around $30 \mathrm{~nm}$ ) layers were formed (shell),

- additionally, phase transformation of austenite into ferrite was observed due to strain introduced during milling,

- the harmonic structure was preserved in the sintered samples, thus the final structure consisted of microcrystalline cores embedded in the nanocrystalline matrix,

- $\quad$ the influence of the applied sintering temperature manifested in density and hardness increase rather than in phase composition,

- $\quad$ sintering processes restored the phase composition existing before milling, i.e., austenite with some contribution of ferrite.

Author Contributions: Conceptualization, D.O.; methodology, D.O., A.S.; software, G.C.; validation, D.O., A.S. and G.C.; formal analysis, D.O. and A.S.; investigation, A.S. and G.C.; resources, A.S.; data curation, A.S., G.C. and D.O.; writing—original draft preparation, A.S.; writing—review and editing, D.O.; visualization, A.S. and D.O.; supervision, D.O. All authors have read and agreed to the published version of the manuscript.

Funding: This research received no external funding.

Institutional Review Board Statement: Not applicable.

Informed Consent Statement: Not applicable.

Data Availability Statement: Not applicable.

Acknowledgments: The authors acknowledge Łukasz Żrodowski for powder manufacturing and Bartosz Michalski for sintering processes and density measurements assistance.

Conflicts of Interest: The authors declare no conflict of interest.

\section{References}

1. Suryanarayana, C. Mechanical alloying and milling. Prog. Mater. Sci. 2001, 46, 1-184. [CrossRef]

2. Sekiguchi, T.; Ono, K.; Fujiwara, H.; Ameyama, K. New microstructure design for commercially pure titanium with outstanding mechanical properties by mechanical milling and hot roll sintering. Mater. Trans. 2010, 51, 39-45. [CrossRef] 
3. Vajpai, S.K.; Ota, M.; Zhang, Z.; Ameyama, K. Three-dimensionally gradient harmonic structure design: An integrated approach for high performance structural materials. Mater. Res. Lett. 2016, 4, 191-197. [CrossRef]

4. Sawangrat, C.; Kato, S.; Orlov, D.; Ameyama, K. Harmonic-structured copper: Performance and proof of fabrication concept based on severe plastic deformation of powders. J. Mater. Sci. 2014, 49, 6579-6585. [CrossRef]

5. Vajpai, S.K.; Sawangrat, C.; Yamaguchi, O.; Ciuca, O.P.; Ameyama, K. Effect of bimodal harmonic structure design on the deformation behaviour and mechanical properties of Co-Cr-Mo alloy. Mater. Sci. Eng. C 2016, 58, 1008-1015. [CrossRef]

6. Vajpai, S.K.; Choncharoen, S.; Ameyama, K. Harmonic structure design of Co-Cr-Mo alloy with outstanding mechanical properties. Adv. Mater. Res. 2013, 939, 60-67.

7. Ota, M.; Shimojo, K.; Okada, S.; Vajpai, S.K.; Ameyama, K. Harmonic structure design and mechanical properties of pure Ni compacts. J. Powder Metall. Min. 2014, 3, 122.

8. Zhang, Z.; Orlov, D.; Vajpai, S.K.; Tong, B.; Ameyama, K. Importance of bimodal structure topology in the control of mechanical properties of a stainless steel. Adv. Eng. Mater. 2015, 17, 791-795. [CrossRef]

9. Zhang, Z.; Vajpai, S.K.; Orlov, D.; Ameyama, K. Improvement of mechanical properties in SUS304L steel through the control of bimodal microstructure characteristics. Mater. Sci. Eng. A 2014, 598, 106-113. [CrossRef]

10. Fujiwara, H.; Kawabata, T.; Miyamoto, H.; Ameyama, K. Mechanical properties of harmonic structured composite with pure titanium and Ti-48at\%Al by MM/SPS process. Mater. Trans. 2013, 54, 1619-1623. [CrossRef]

11. Vajpai, S.K.; Ota, M.; Watanabe, T.; Maeda, R.; Sekiguchi, T.; Kusaka, T.; Ameyama, K. The development of high performance Ti-6Al-4V alloy via a unique microstructural design with bimodal grain size distribution. Metall. Mater. Trans. 2015, 46A, 903-914. [CrossRef]

12. Zhou, G.; Ma, H.; Zhang, Z.; Sun, J.; Wang, X.; Zeng, P.; Zheng, R.; Chen, X.; Ameyama, K. Fatigue crack growth behavior in a harmonic structure designed austenitic stainless steel. Mater. Sci. Eng. A 2019, 758, 121-129. [CrossRef]

13. Nakai, Y.; Kikuchi, S.; Osaki, K.; Kawabata, M.O.; Ameyama, K. Effects of rolling reduction and direction on fatigue crack propagation in commercially pure titanium with harmonic structure. Int. J. Fatigue 2021, 143, 106018. [CrossRef]

14. Li, G.; Lyu, S.; Zhang, R.; Kawabata, M.O.; Ma, C.; Li, Q.; Ameyama, K. Further optimization of strength and ductility in a harmonic structure designed pure copper via thermomechanical processing. Mater. Sci. Eng. A 2020, 790, 139687. [CrossRef]

15. Li, G.; Liu, M.; Lyu, S.; Nakatani, M.; Zheng, R.; Ma, C.; Li, Q.; Ameyama, K. Simultaneously enhanced strength and strain hardening capacity in FeMnCoCr high-entropy alloy via harmonic structure design. Scr. Mater. 2021, 191, 196-201. [CrossRef]

16. Fujiwara, H.; Inomoto, H.; Sanada, R.; Ameyama, K. Nano-ferrite formation and strain-induced-ferrite transformation in an SUS304L austenitic stainless steel. Scr. Mater. 2001, 44, 2039-2042. [CrossRef]

17. Oleszak, D.; Grabias, A.; Pękała, M.; Świderska-Środa, A.; Kulik, T. Evolution of structure in austenitic steel powders during ball milling and subsequent sintering. J. Alloys Comp. 2007, 434-435, 340-343. [CrossRef] 